\title{
Ovarian Surgery and Ovarian Reserve: The Application of Temporary Compression for Natural Hemostasis to Eliminate Exposure of the Ovary to Chemical Agents and Physical Energies
}

\author{
VG Zhegulovych*1, BM Ventskovsky ${ }^{1}$ and Yu V Zhegulovych ${ }^{2}$ \\ ${ }^{1}$ OO Bohomolets National Medical University, Ukraine \\ ${ }^{2}$ Kyiv City Clinical Hospital \#18, Ukraine \\ Received: 漹 August 17, 2018; Published: August 22, 2018 \\ *Corresponding author: VG Zhegulovych, Kyiv City Clinical Hospital \#18, Ukraine
}

\section{Short Communication}

Surgical interventions are primarily associated with the need for hemostasis. All types of energy (mechanical, electrical, thermal, welding, laser, etc.) as well as chemical adhesives and sealants that are used in surgery affect the ovarian tissue and damage the ovarian reserve in women of reproductive age to a different extent depending on various pathophysiological mechanisms [1-4]. Ovarian suturing causes an intense inflammatory reaction of the tissue to the foreign body (tissue necrosis, granulation tissue) even in the case when the suture material dissolves within 30-60 days.

Conservative hemostasis methods involving temporary compression are widely used in surgery to treat liver damage and control acute gastroduodenal ulcer bleeding. Thus, compression hemostasis can be suggested as an alternative to thermal and ultrasound methods in terms of minimizing the impact on the ovarian reserve.

Taking into account the peculiarities of ovarian blood supply, as well as natural monthly traumatization of the ovaries accompanied by the formation of hematomas in the area of an ovulation stigma, it was decided to use temporary compression of the ovarian tissue to achieve hemostasis.

The first step includes placement of DeBakey Atraumatic Bulldog Clamps (Figure 1) on lig. infundibulopelvicum and lig. ovarii proprium followed by the injection of vasopressor into the mesosalpinx and mesovarium (Figure 1). The vasopressor agent is introduced in the form of solution containing 3-4 drops of adrenaline per $100 \mathrm{ml}$ of saline. The vasopressor provides a temporary constriction of the blood vessels - up to 20-30 minutes, which prevents blood loss during surgery. When vasopressor is administered, the amount of blood that is lost ranges from 20 to 40 $\mathrm{ml}$, compared to $200-300 \mathrm{ml}$ without its use. As a result, surgical intervention on the ovary is performed with minimal capillary hemorrhage and without coagulation (Figure 2). This method allows us to remove various types of cysts including endometrioid ovarian cysts, dermoid ovarian cysts, corpus luteal cysts.

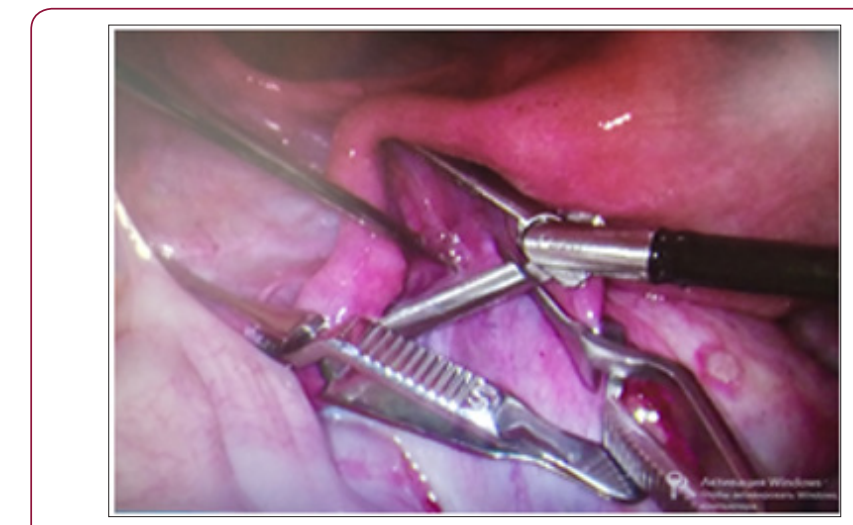

Figure 1: Vascular bulldog clamps on lig. infundibulopelvicum and lig. ovarii proprium and injection of vasopressor into the mesosalpinx.

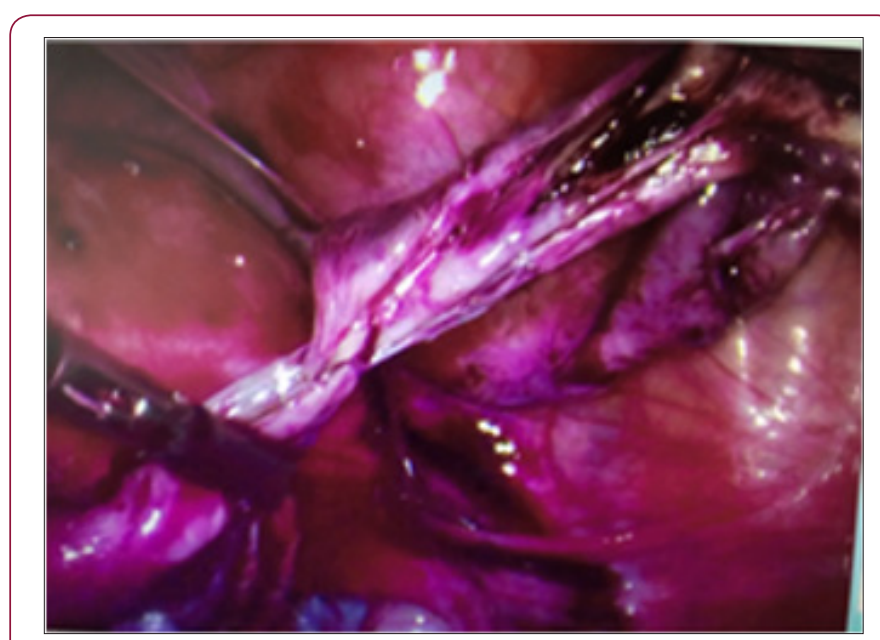

Figure 2: Removal of the cystic capsule. 
The next step includes ovarian compression. Three options have been investigated and are proposed by this study.

Stitching: Compression through ventrosuspension is performed with the monofilament thread. The ovarian walls (Figure 3) are stitched with a Z-like suture performed by a straight needle and the ovary itself is tethered to the abdominal wall (Figure 3).
Simultaneously, the gauze swab is applied to the skin to control the tension of the thread and prevent its overtension and cutting through the ovary. 6-8 hours after the operation stabilization of clots is completed due to natural hemostasis in the ovary, which makes it possible to easily remove the slippery filament. After that, the ovary returns to its natural location.
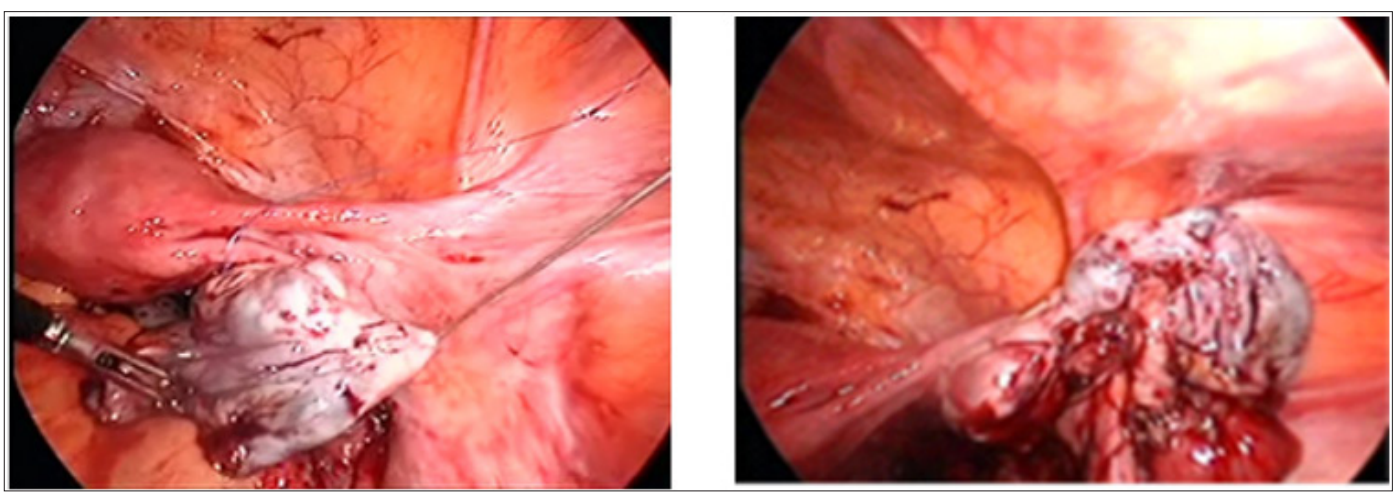

Figure 3: Stitching and ventrosuspension of the ovary with the monofilament thread.

Compression with the Foley catheter: Once the ovarian cyst is emptied and the cystic capsule is removed, the ovarian tissue becomes a thin-walled structure. Thinning of the ovarian tissue can be observed due to its distribution and stretching out over the cyst. Stitching of the thinned ovarian tissue with the monofilament thread is difficult because the thread may cut through. As soon as a 5 $\mathrm{mm}$ trocar penetrates the ovarian tissue, the Foley urinary catheter No5 or No6 is inserted through the trocar. The balloon is inflated
(Figure 4) and the trocar is removed. The inflated rubber balloon does not press the ovary tightly to the abdominal wall (Figure 4). Chromohydrotubation is the next step. The balloon is deflated and the catheter is removed after 6-8 hours. During this time, the natural hemostasis stops bleeding. As the ovary does not manage to fix itself to the abdominal wall at the point of its temporary location, no adhesions form afterwards. Once the catheter is removed, the ovary returns to its natural location in the lower abdomen.
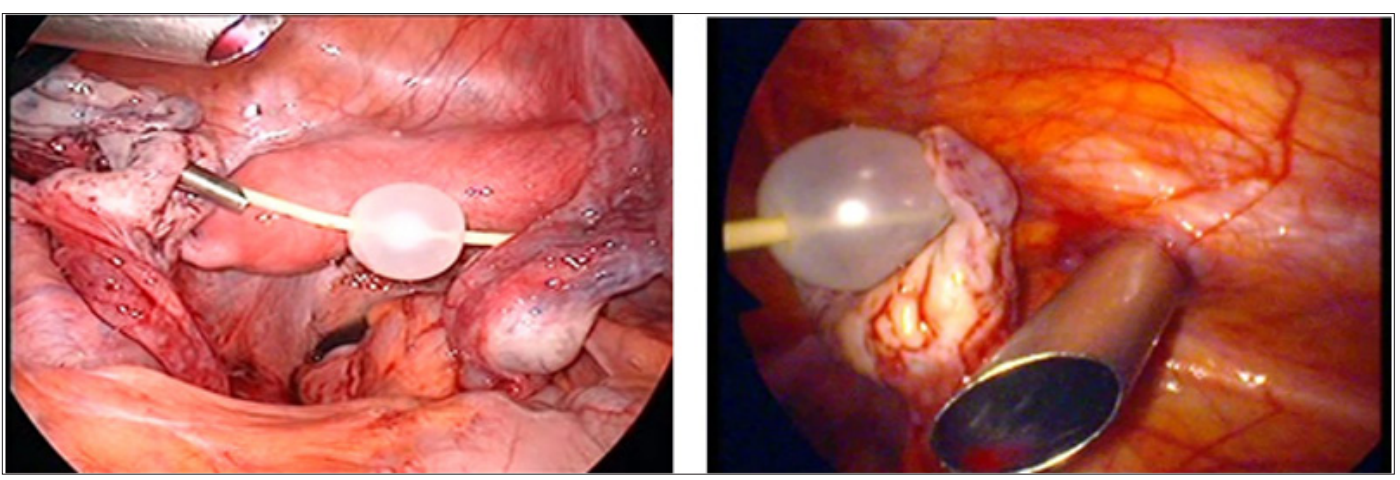

Figure 4: Compression and ventrosuspension of the ovary with the Foley catheter.
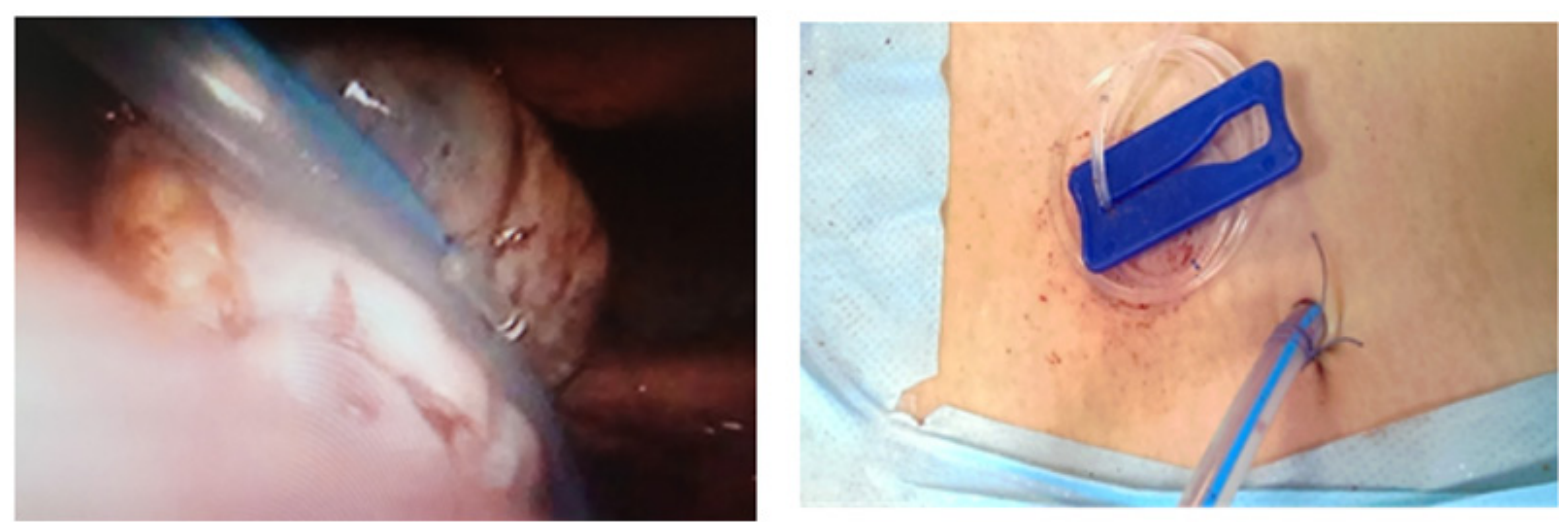

Figure 5: Compression and ventrosuspension of the ovary with the help of drainage and T-lifting system. 
Compression with the help of T-lifting performed by a needle which serves as a passage for a plastic tube with a T-shaped plastic end: The T-lift needle is inserted through the abdominal wall and guided through both walls of the ovary and the drainage tube. Then the T-shaped plastic end of the T-lift is released, the needle is removed and the T-lift is tethered to the abdominal wall. The drainage tube thus provides compression of the ovary in the abdominal cavity (Figure 5). The external view can be seen below (Figure 5). The T-lift is cut away during the drainage tube removal taking place after 6-8 hours.

The above methods are based on the general concept of compression hemostasis. The type of ventrosuspension is chosen depending on each individual case. It allows us to control the degree of damage to the ovary. Temporary ventrosuspension of the ovary with such an adjustable compression hemostasis does not affect the patency of the fallopian tube. Within several hours the blood circulation is restored without any interference with normal functioning of the ovary since thrombosis never develops here and the ovary itself periodically undergoes natural traumatization and ischemia during the menstrual cycle.

As soon as compression through ventrosuspension is completed, the clamps are removed and assessment of hemostasis is conducted. For this purpose, the place of penetration or incision is irrigated with saline solution to determine the presence and location of a possible bleeding. It allows us to control the tension of the compression mechanism (thread, Foley catheter, T-lift) until bleeding is completely stopped. Chromohydrotubation is done where a colored dye (methylene blue) is injected into the uterine cavity. In the abdominal cavity, the dye should be observed as it comes out of the end of the tube to confirm its patency. Once assessment of hemostasis and aspiration of the fluid from the pelvic region are completed, other laparoscopic instruments and laparoscope are removed. After 6-8 hours, compression mechanisms and instruments are also removed, as noted above.

148 operations on the ovary were performed with the application of the described method: 66 - with fixation by the filament, 49 - with fixation by the Foley catheter and 33 - with the
T-lifting system. Prior to surgery and in the postoperative period, the main indicators characterizing the state of the ovarian reserve (AMH, FSH, LH, InB), the number of antral follicles and blood flow parameters were controlled. Patient monitoring continues.

The research demonstrates that temporary compression hemostasis allows us to perform almost bloodless surgical intervention on the ovary and avoid the application of aggressive coagulation and other physical (laser, ultrasound) energies as well as chemical (various adhesives) agents that adversely affect the follicular apparatus of the ovary [6-9].

\section{References}

1. Ata B, Turkgeldi E, Seyhan A, Urman B (2015) Effect of hemostatic method on ovarian reserve following laparoscopic endometrioma excision; comparison of suture, hemostatic sealant, and bipolar dessication. A systematic review and meta-analysis. J Minim Invasive Gynecol 22(3): 363-372.

2. Ben-Shian Huang, Peng-Hui Wang, Hsiao-Wen Tsai, The-Fu Hsu, MingShyen Yen, et al. (2014) Single-port compared with conventional laparoscopic cystectomy for ovarial dermoid cysts. Taivanese Journal of Obstetrics \& Gynecology 53: 523-529.

3. Hye yon Cho, Sung Taek Park, Min Sun Kyung, Sung-ho Park (2017) Assessment of ovarian reserve after hysterectomy: laparoscopic vs. nonlaparoscopic surgery. EJOG 210: 54-57.

4. Zhang CH, Wu L, Li PQ (2016) Clinical study of the impact of ovarian reserve by different hemostasis methods in laparoscopic cystectomy for ovarian endometrioma. Taiwan J Obstet Gynecol 15(4): 507-511.

5. Kang JH, Kim YS, Lee SH, Kim WY (2015) Comparing of hemostatic sealants on ovarian reserve during laparoscopic ovarian cystectomy. Eur J Obstet Gynecol Reprod Biol 194: 64-67.

6. Asgari Z, Rouholamin S, Hosseini R, Sepidarkish M, Hafizi L, et al. (2015) Comparing ovarian reserve after laparoscopic excision of endometriotic cysts and hemostasis achieved either by bipolar coagulation or suturing: a randomized clinical trial. Arch Gynecol Obstet 293(5): 1015-1022

7. Zaitoun M, Zaitoun M, El Behery M (2013) Comparing long-term impact on ovarian reserve between laparoscopic ovarian cystectomy and open laparotomy for ovarian endometrioma. J Ovarian Res 6(1): 76.

8. Roman H, Pura I, Tarta O, Mokdad C, Auber M, et al. (2011) Vaporization of ovarian endometrioma using plasma energy: histologic findings of a pilot study. Fertil Steril 95(5): 1853-1856.

9. Song T, Kim WY, Lee KW, Kim KH (2015) Effect on ovarian reserve of hemostasis by bipolar coagulation versus suture during laparoendoscopic single-site cystectomy for ovarian endometriomas. J Minim Invasive Gynecol 22(3): 415-420.

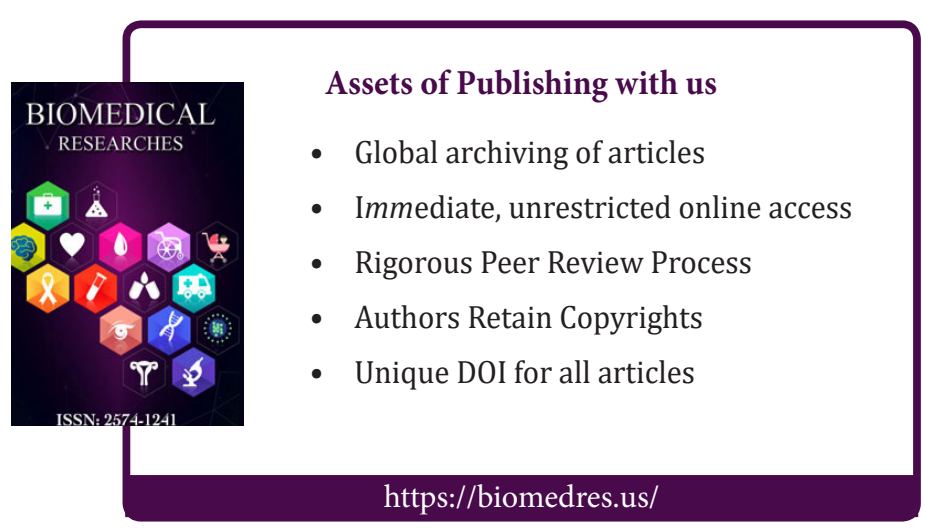

ISSN: 2574-1241

DOI: 10.26717/BJSTR.2018.08.001628

Ya-Lie Ku. Biomed J Sci \& Tech Res

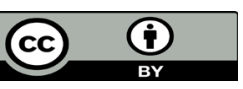

This work is licensed under Creative Commons Attribution 4.0 License

Submission Link: https://biomedres.us/submit-manuscript.php 